\title{
The Effect of Facing Dying Patients on Medical Students - An Outcome Evaluation
}

\author{
T. Thyson, M. Schallenburger, A. Scherg, J. Schwartz, M. Neukirchen \\ Universitätsklinikum Düsseldorf - Interdisziplinäres Zentrum für Palliativmedizin \\ lehre.palliativmedizin@med.uni-duesseldorf.de
}

\section{Background and Study Objective}

Medical students in the clinical part of the curriculum have the opportunity to encounter palliative patients in an elective subject. Students expand their knowledge about end-of-life communication, practice their communication skills and improve professional handling of their own emotions. Preliminary to the conversation, students complete an e-learning course. After the encounter they reflect their experiences in a written review, followed by a reflection seminar. The aim of this study was to identify potentially cognitiveaffective change, notably attitudinal change related to personal encounter with terminally ill by using an outcome-based evaluation.

\section{Method}

Beside global evaluation of learning outcomes, specific outcome of learning objectives and learning increase (CSA gain) were assessed. Outcomes were examined by comparative self-assessment (CSA) ${ }^{1}$ of 14 items, presenting specific study goals in a pre-post (e. g. prospective) and post-then (e. g. retrospective) procedure, respectively. Learning gain was calculated using the following formula ${ }^{1}$ :

CSA gain $(\%)=(($ Mean pre - Mean post $) /($ Mean pre -1$)) \times 100)$

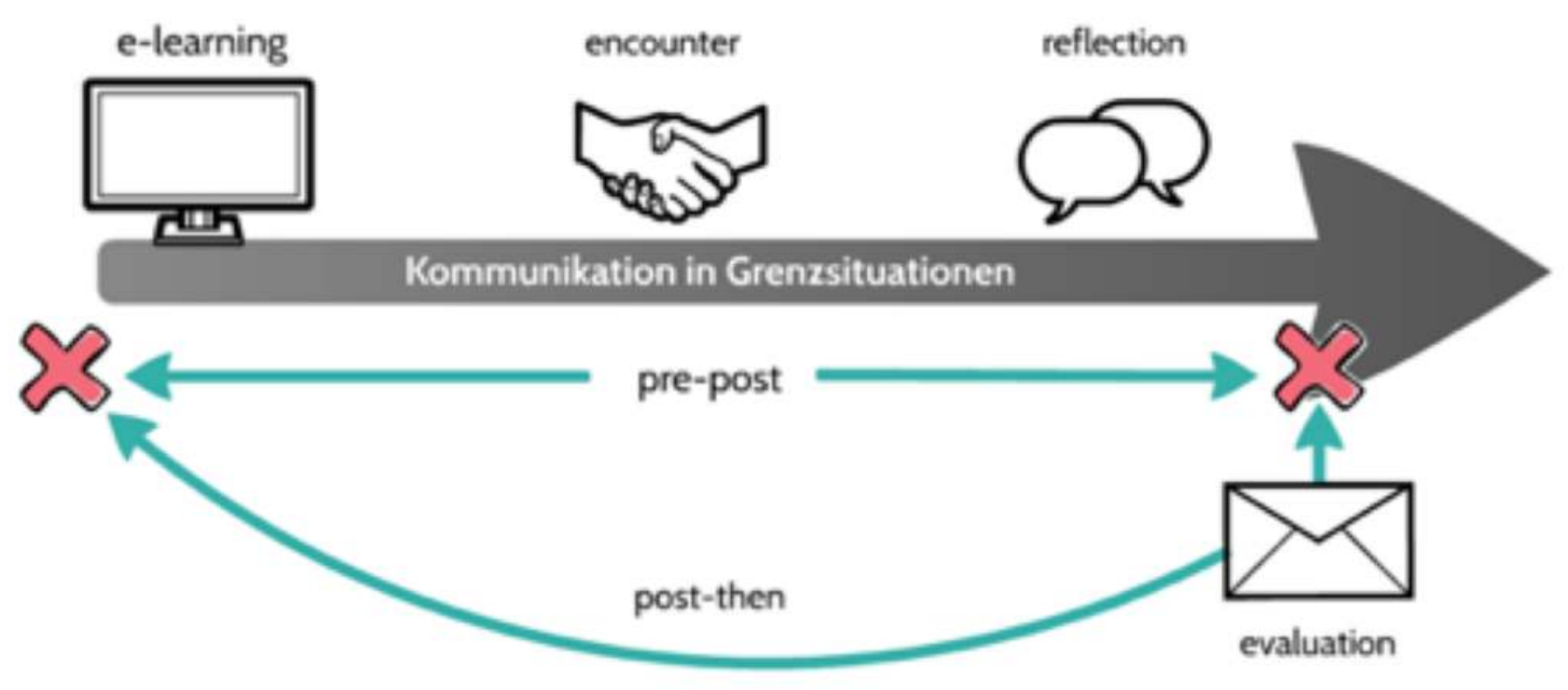

\section{Results}

The cohort (between April 2018 - March 2019) included 30 medical students. Post-then comparisons showed sizeable increase in learning abilities by ten out of 14 items (range $25.71 \%$ up to $69.14 \%$ ). As table 1 shows highest CSA gain was identified by approach to own emotions while facing a terminally ill, definition of the NURSE communication model and meeting a seriously ill person without fear. Withstanding confrontation with its own finiteness of life revealed less learning increase. The slightest increase in learning was seen in the use of non-verbal techniques in conversations. However, for this item in the prepost procedure the students showed over $50 \%$ learning gain, but the retrospective self-assessment shows the actual and in this case lower increase in learning.

Table 1

Means of the post-then self assesment and CSA Gain

\begin{tabular}{lccc}
\hline Item & $\begin{array}{c}\text { Retrospective } \\
\text { Mean }\end{array}$ & $\begin{array}{c}\text { Current } \\
\text { Mean }\end{array}$ & CSA Gain \\
\hline $\begin{array}{l}\text { I can accept my own emotional reaction to } \\
\text { experiencing borderline situations from a } \\
\text { patient perspective. }\end{array}$ & 2.75 & 1.54 & $69.14 \%$
\end{tabular}
patient perspective.

I can explain the NURSE model for dealing with emotions in detail in a conversation.

I can meet a seriously ill person without fear.

I can endure a direct confrontation with my own finiteness. conversation with seriously ill patients.

Note. $n=30$

\section{Discussion}

The chosen compulsory subject supports medical students not only in terms of gaining knowledge and skills, but also promotes development of attitude and emotional engagement on the subject of death and dying. In addition, the results show in which aspects of communication with seriously ill and dying people students require targeted support. As a long term outcome, higher medical communication skills could improve the physician-patient-relationship.

In addition, the evaluation shows indications of a response shift bias, a phenomenon that has already been shown in other teaching evaluations ${ }^{2}$. Students provided inconsistent responses in pre-post-tests compared to post-then-tests. In our study, students overestimate themselves in using nonverbal techniques in the pre-post procedure (CSA gain 51.40\%). The retrospective self-assessment in the post-then procedure shows the considerable lower actual increase in learning (see Table 1). Overall, there are only negligible differences between pre-post and post-then comparisons.

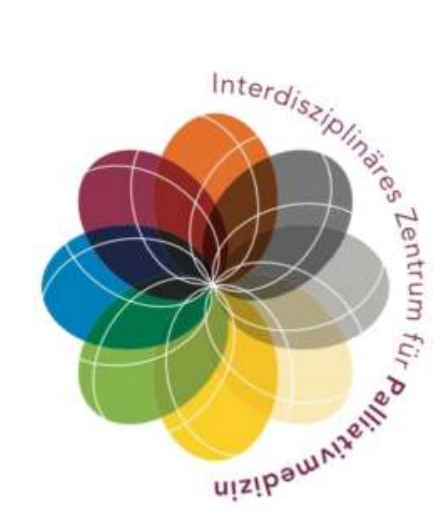

